\title{
High-Fat-High-Fructose Diet Decreases Hippocampal Neuron Number in Male Rats
}

\author{
Inggita Kusumastuty ${ }^{1}$, Frinny Sembiring ${ }^{1}$, Sri Andarini², Dian Handayani ${ }^{1, *}$ \\ ${ }^{1}$ Department of Nutrition, Faculty of Medicine, Universitas Brawijaya, Jl. Veteran, Malang 65145, Indonesia \\ ${ }^{2}$ Department of Medical Doctor Education, Faculty of Medicine, Universitas Brawijaya, Jl. Veteran, Malang 65145, Indonesia \\ *Corresponding author. E-mail: handayani_dian@ub.ac.id
}

Received date: May 28, 2019; Revised date: Sep 17, 2019; Accepted date: Sep 23, 2019

\section{Abstract}

$\mathrm{B}$ ACKGROUND: Consumption of foods and drinks high in energy, fat, and/or sugar beyond the recommended quantities can cause obesity, which triggers the incidence of brain nerve cell death related to oxidative stress, high levels of tumor necrosis factor (TNF)- $\alpha$ and triglycerides, and low high-density lipoprotein (HDL) levels. Progressive nerve cell death causes decreasing cognitive performance. This study aims to prove that an American Institute of Nutrition committee in 1993 (AIN93M) diet modified with high-fat-high-fructose (HFHF) can decrease the number of hippocampal neurons. A decrease in the number of hippocampal neurons indicates progressive nerve cell death.

METHODS: An experimental study using a post-test control group design was carried out using male Sprague Dawley rats. Samples were selected using simple random sampling to divide them into two groups, Group I was AIN-

\section{Introduction}

The consumption of foods and drinks high in energy, fat and/or sugar is escalating throughout the world. Several studies have shown that the administration of high-fathigh-fructose (HFHF) diets in experimental animals causes metabolic complications, commonly known as metabolic syndrome, for example obesity, dyslipidaemia, insulin resistance, impaired glucose tolerance, hyperinsulinaemia, and increased systolic blood pressure.(1,2) An HFHF diet causes obesity associated with hyperlipidaemia
93M-modified HFHF diet $(\mathrm{n}=14)$ and Group II was AIN$93 \mathrm{M}$ standard $(\mathrm{n}=16)$. The number of visible neurons was measured in the hippocampus area of Sprague Dawley rats' brains, stained with haemotoxylin and eosin (H\&E) and scanned under 400x magnification. Neurons were counted in 10 visual fields using the "Cell_Count" application.

RESULTS: The data were analysed by Pearson's correlation test using SPSS. The results show that rats in Group I had a greater weight gain and fewer neurons than those in the Group II ( $p=0.023, \mathrm{r}=-0.413)$.

CONCLUSION: The consumption of foods high in fat and fructose can cause an increase in nerve cell death, as shown by the decrease in the number of hippocampal neurons.

KEYWORDS: brain nerve cells, high fat, high fructose, increased body weight

Indones Biomed J. 2020; 12(1): 1-7 and endothelial dysfunction.(3) Obesity is a condition of excessive fat deposits in adipose tissue (4), and an individual is considered obese if their body mass index (BMI) is greater than or equal to $30 \mathrm{~kg} / \mathrm{m}^{2}$. Based on data from the 2016 National Health Survey/Survei Indikator Kesehatan Nasional (SIRKESNAS), the national prevalence of individuals with a BMI $25-27$ was $33.5 \%$, whereas the prevalence of individuals with a BMI $\geq 27$ reached $20.6 \%$. The prevalence of obesity in men $(24.0 \%)$ was lower compared to women (41.4\%), and according to age group, the highest prevalence of obesity was in the 40-49 year age group, being as high as $38.8 \%$.(5) 
It has been shown that increasing BMI and waist circumference significantly correlate with a decrease or failure of cognitive function; individuals who are overweight or obese have a 2.34 times higher risk of developing dementia, and individuals with central obesity have a 3.60 times higher risk of developing dementia.(610) A BMI greater than 30 causes shortening fibre bundle length (FBL), and in turn shortened FBL contributes to atrophy in the brain and decreased survival rate of nerve cells, especially in the frontal and pariental cortices.(1113) While central obesity that can be indicated by waist circumference $(>102 \mathrm{~cm}$ in men and $>88 \mathrm{~cm}$ in women) is associated with various neuroendocrine disorders, such as increasing cortisol levels associated with hippocampal atrophy and resulting in reduced memory function, leading to increased risk of suffering from dementia despite having a normal weight. In addition, the blood flow in the brain's gray matter matrix is reduced by $15 \%$. $(14,15)$

The previous study stated that the white-matter volume of obese individuals aged 50 years is equivalent to 60 year-old individuals with normal BMIs, suggesting that the brains of obese individuals age by 10 years.(6) Another study showed that the impact of obesity does not only occur in maturity but also has effects in childhood. Increased body weight is associated with decreased short-term memory and visuospatial coordination in children and increases the risk of dementia in adulthood. The results of these studies indicate that obesity has an impact on age-related structural brain changes.(16)

This information highlights the need to do this research that aims to prove that an American Institute of Nutrition committee in 1993 (AIN-93M)-modified HFHF diet can decrease the number of hippocampal neurons.

\section{Methods}

\section{Research Design}

This was a randomized post-test control group study. The ethical clearance was obtained from the Medical Research
Ethics Commission of the Faculty of Medicine, Universitas Brawijaya (No. 368/EC/KEPK/10/2017).

In this study, male Sprague Dawley rats that fulfilled the inclusion criteria were randomly divided into two groups, the standard AIN-93M feed group (Group I) and the AIN-93M-modified HFHF feed group (Group II). The Group I consisted of 16 rats, and Group II consisted of 14 rats. The minimum sample size was determined using Federer's formula. The rats were adapted for 4 weeks and then continued with the intervention for 17 weeks.

\section{Fructose Feeding}

The composition of the AIN-93M standard feed was corn starch, dextrinized corn starch, sucrose, soybean oil, casein, egg-white flour, agar, minerals, and vitamin mix of AIN, 1-cysteine, choline bitartrate, tertiary butylhydroquinone (TBHQ). Meanwhile, the composition of the AIN-93Mmodified HFHF feed was corn starch, dextrinized corn starch, sucrose, fructose, lard, soybean oil, casein, egg-white flour, agar, minerals, and vitamin mix of AIN, 1-cysteine, choline bitartrate, TBHQ. The nutrient composition per 100 grams of each rat diet is presented in Table 1. The drink given to Group II was 30\% fructose liquid containing 0.3 $\mathrm{kcal} / \mathrm{mL}$ energy and $1.2 \mathrm{~g} / \mathrm{mL}$ carbohydrate.

\section{Dietary Intake and Weight}

The diet was given ad libitum and contained $20 \mathrm{~g} / \mathrm{day} / \mathrm{rat}$ feed and $250 \mathrm{~mL} /$ day drink. The actual intake of food and drink was calculated by subtracting the the remaining food (gram) and drink (mL) per 24 hours from the initial weight. The data were used to calculate energy intake (kcal), protein (gram), fat (gram), and carbohydrate (gram). The rats were weighed once a week to determine their body weight.

\section{Analysis of Neurons Number}

At the end of the study, rats were anesthetised by injecting $0.3 \mathrm{~mL}$ of ketamine in the intramuscular section, followed by surgery. The obtained brains were preserved in $10 \%$ formalin buffer and closed tightly. A standard histology examination was carried out by hematoxylin and eosin

Table 1. Nutritional composition per 100 grams of rat feed.

\begin{tabular}{lcc}
\hline \multicolumn{1}{c}{ Nutritional Composition } & Standard AIN-93M & HFHF Modified AIN-93M \\
\hline Energy (kcal) & 421 & 508 \\
Carbohydrates (gram; \%) & $45.12 ; 42.87 \%$ & $37.32 ; 29.39 \%$ \\
Protein (gram; \%) & $32.96 ; 31.32 \%$ & $27.68 ; 21.80 \%$ \\
Fat (gram; \%) & $12.07 ; 25.81 \%$ & $29.14 ; 51.64 \%$ \\
Energy Density (kcal/gram) & 4.21 & 5.08 \\
\hline
\end{tabular}


Table 2. Food and nutrients intake.

\begin{tabular}{lcc}
\hline \multirow{2}{*}{\multicolumn{1}{c}{ Intake }} & \multicolumn{2}{c}{ Treatment } \\
\cline { 2 - 3 } & Group I & Group II \\
\hline Feed (gram) & $12.02 \pm 1.62 *$ & $6.31 \pm 1.12 *$ \\
Fructose Drink (mL) & - & $29.73 \pm 3.88$ \\
Energy (kcal) & $50.60 \pm 6.85^{*}$ & $67.75 \pm 6.38^{*}$ \\
Carbohydrates (gram; \%) & $5.42 \pm 0.73^{*} ; 43.0 \%$ & $11.27 \pm 1.13 * ; 66.5 \%$ \\
Protein (gram; \%) & $3.96 \pm 0.53 * ; 31.3 \%$ & $1.74 \pm 0.31 * ; 10.3 \%$ \\
Fat (gram; \%) & $1.86 \pm 0.25 * ; 33.0 \%$ & $2.36 \pm 0.41 * ; 31.4 \%$ \\
\hline
\end{tabular}

*: showed that the two groups differed significantly $(p<0.05)$. All values are presented in the mean $\pm \mathrm{SD}$ form.

(H\&E) staining, covering the steps of fixation, dehydration, cleaning, impregnation/embedding, blocking, sectioning, and staining. The H\&E stained samples were scanned under 400x magnification in the hippocampal area using an Olympus dot slide microscope. Subsequently, the number of nerve cells was count in 10 visual fields, assisted by the "Cell_Count" application.

\section{Processing and Analysis of Data}

Data were processed using SPSS software version 18 . All data were presented as the mean \pm standard deviation (SD). The relationship between increasing body weight and decreasing neurons was analysed using Pearson's correlation test.

\section{Results}

\section{Dietary Intake and Weight}

The average food intake of Group II was smaller than Group

I. However, the average energy and carbohydrate intake

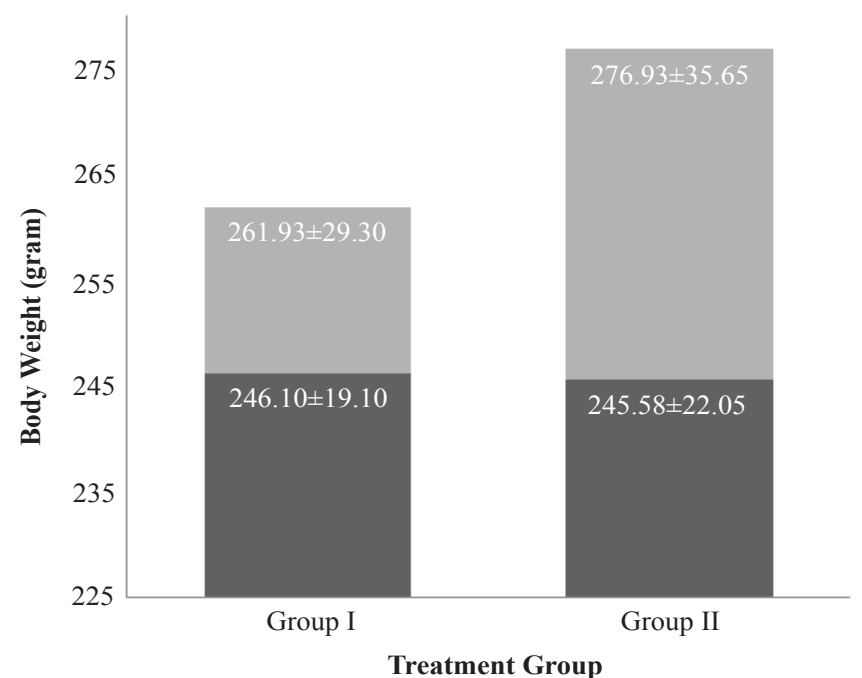

was greater in the Group II compared to the Group I. The average food and intake of rats per day was significantly different between both groups (Table 2).

Rats in each treatment group experienced weight gain during the study. Rats in the Group I increased in body weight, during the intervention, by up to 31.33 gram and in the Group II by 15.82 gram (Figure 1). However, the initial body weight, final body weight, and changes in body weight were not significantly different between the two groups.

There was a significant correlation between the average of food intake, protein, and fat on the increase in rat body weight in Group II. There was no significant correlation between weight gain and energy intake or protein intake in Group II or any of the feed and nutrient parameters in Group I. Details of the correlation between the average food intake and the increase in rat body weight is presented in Table 3.

\section{Number of Neurons in Rats}

The number of neurons in the Sprague Dawley rats is presented in Table 4, and the calculation used to determine

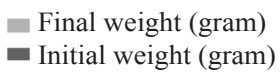

Figure 1. The average body weight of rats in both groups. 
Table 3. The correlation between food and nutrition intake on weight increase.

\begin{tabular}{lcc}
\hline \multirow{2}{*}{ Treatment Group } & p-value* & r** \\
\cline { 2 - 3 } Increased Weight & \\
\hline Group I & 0.136 & - \\
Feed & 0.136 & - \\
Energy & 0.137 & - \\
Carbohydrates & 0.135 & - \\
Protein & 0.137 & - \\
Fat & & - \\
\hline Group II & $0.002 *$ & - \\
Feed & 0.67 & - \\
Energy & 0.943 & 0.723 \\
Carbohydrates & $0.002 *$ & 0.725 \\
Protein & $0.001 *$ & \\
Fat & &
\end{tabular}

*p-value was analysed with Pearson correlation test $(p<0.05$ means there was correlation); $* *=$ relationship/correlation strength.

the number of rat neurons in the hippocampal area in each treatment in one field of view is given in Figure 2.

The number of rat neurons in Group I (2072.07 neurons) was higher than in Group II (1679.25 neurons), and the difference between the number of neurons in the two groups was quite large, 392.82 cells, although this difference was not statistically significant $(p>0.05)$. There was a significant negative correlation $(\mathrm{r}=-0.413, p=0.023)$ between the increasing body weight and the number of neurons in the Sprague Dawley rats.

\section{Discussion}

The feed intake in the AIN-93M-modified HFHF group was lower than in the control group (standard diet). The intake of drink containing fructose is thought to be the cause of the low intake, as it has been suggested that the intake of fructose drink could suppress solid food intakes.(17) Low feed intake is also influenced by rat feed factors. Rats prefer food that is dry, solid, coarse texture, and hard in consistency (18), whereas the AIN-93M modified HFHF diet tended to be oily and slightly soft due to its high fat content (51.64\%). The addition of lard can also cause the feed to easily oxidise and turn rancid. HFHF feed has a higher energy and fat content compared to the standard diet so the consumption of HFHF feed should cause rapid satiety. Some previous studies were also in line with this study, in which they showed that the feed intake of rats given a HFHF diet was lower than rats fed the standard/normal diet.(19-21)

Rat body weight in each treatment group experienced an increase during the study, but the increases were not statistically significant. Foods with high density increase energy intake (22), and high energy intake in the body will be stored as fat, leading to weight gain. In this study, HFHF feed had a higher energy density (5.08) than the standard feed (4.21). Calorie intake does not significantly affect changes in body weight but does significantly affect fat mass.(23) This could be the reason why weight gain during the study was not significant in either of the two groups. Thus, an increase in body weight alone does not indicate the incidence of obesity; there are other factors that must be considered, such as changes in body composition. (24) The results show that the higher the amount of fat in the diet, given to Sprague Dawley rats, the greater the weight gain. (25)

Based on the results of the calculation, it was found that the average number of neurons in rats given the HFHF diet (1679.25 \pm 737.21$)$ was smaller than the rats given the standard diet $(2072.07 \pm 657.96)$, and there was no significant difference between the number of rat neurons between the two groups. However, in this study, there was a significant negative correlation between increasing body weight and the number of neurons in Sprague Dawley rats. A decreasing number of neurons indicates progressive nerve cell death. Our study suggests that HFHF did not directly link to influence neuron number. High-fat and high-fructose intake accumulate adipocyte and lead to obesity. Obesity

Table 4. Number of rat brain nerve cells.

\begin{tabular}{lcc}
\hline \multirow{2}{*}{ Brain Nerve Cells } & Group I & Mean \pm SDD \\
\cline { 2 - 3 } & $2072.07 \pm 657.96$ & $1679.25 \pm 737.21$ \\
\hline Average number of brain nerve cells & 591 & 487 \\
Min number of brain nerve cells & 3410 & 2850 \\
Max number of brain nerve cells & & \\
\hline
\end{tabular}



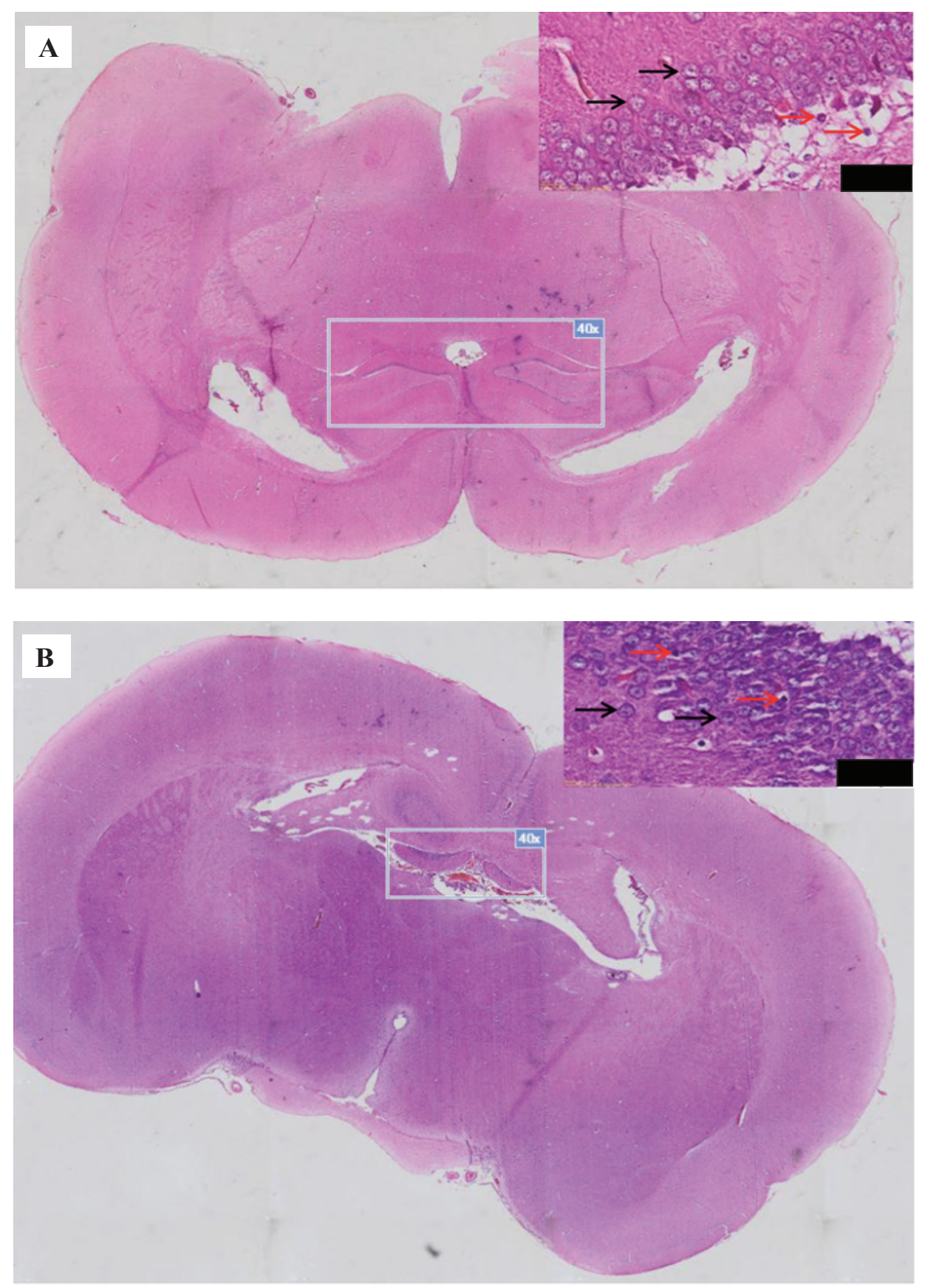

Figure 2. Overview of the number of rat brain nerve cells in the hippocampus area with 400x magnification. A: Group I, with 113 counted cells; B: Group II, with 62 counted cells. Black arrow: neuron; Red arrow: other cells, such as neuroglia cells. Group II has less neuron than in Group I due to a progressive apoptosis. Black bar: $20 \mu \mathrm{m}$. condition is followed by lipid metabolism disorder through the decreasing of high-density lipoprotein (HDL) level and increasing the triglyceride level. HDL plays pivotal role in reverse cholesterol transport, while the impair of HDL level and the increase of oxysterol level trigger neuron inflammation and lead to synaptic function imbalance. $(26,27)$ Some factors related to obesity that can reduce the number of neurons include oxidative stress, high levels of tumor necrosis factor (TNF)- $\alpha$, triglycerides, and low HDL levels.
In the plasma membrane, TNF- $\alpha$ binds to the death receptor (DR), which is followed by the activation of apoptotic pathways consisting of a set of enzymes, such as tumor necrosis factor receptor (TNFR)-associated death domain (TRADD), that activate apoptotic effectors. High TNF- $\alpha$ activity causes the production of apoptotic effector drivers to increase, triggering the occurrence of apoptosis and eventually leading to the progressive death of nerve cells and neurodegenerative diseases.(28) The neurodegenerative disease was a pathological disease which nerve cells are 
lost its structure and function resulting nerve cells death and the decline of nerve cell number. Many factors are involved in the neurodegenerative such as beta-amyloid accumulation and B12 vitamin deficiency. B12 deficiency causes nervous system-related problems such as depression, psychosis, and poor memory function. B12 has been studied to protect against brain atrophy associated with Alzheimer's and decreased cognitive function.(29) Observation of the number of nerve cells that appear to indicate a decrease in nerve cell density in the area observed.

High triglyceride levels in the blood causes an increase in carbonyl proteins and 4-hydroxynonenal levels (HNE), which are both pro-oxidant substances that can trigger oxidative stress in the nervous system. Increasing reactive oxygen species (ROS) can alter calcium influx in glutamate receptors. Increasing reactive oxygen species (ROS) can alter calcium influx in glutamate receptors, therefore can causes damage to the mitochondrial membrane then induce the release of cytochrome $\mathrm{c}$ and apoptosis-inducing factor (Apaf-1), which results in nerve cell death.(30)

Low HDL levels causes an increase in the metabolism of amyloid precursor protein (APP), and results in increased production of amyloid $\beta$ (A $\beta)$ monomers. $A \beta$ has a neurotoxic effect on nerve cells that causes their progressive death. In addition, the $\mathrm{A} \beta$ monomer is a strong chelating agent against the antioxidant transfer of metal ions in its free form, a situation that triggers oxidative stress. The effect of this oxidative stress on the nervous system is to cause degenerative effects (experiencing stages leading to apoptosis) and the progressive death of nerve cells. $(31,32)$

\section{Conclusion}

Consumption of high-energy foods that are high in fat and fructose can cause an increase in body weight. This body weight increase correlates with an increase in nerve cell death. The higher the increase in body weight, the higher the number of nerve cells die in the hippocampus. Further research needs to be done regarding the relationship of decreased brain nerve cells with cognitive performance in an obese rat model.

\section{Acknowledgements}

This research was funded by the Faculty of Medicine, University of Brawijaya number 28/SK/UN10.7/PN/ BPPM/2017.

\section{References}

1. Coate KC, Scott M, Farmer B, Moore MC, Smith M, Roop J, et al. Chronic consumption on a high-fat/high-fructose diet renders the liver incapable of net hepatic glucose uptake. Am J Physiol Endocrinol Metab. 2010; 299: E887-98.

2. Panchal SK, Poudyal H, Iyer A, Nazer R, Alam A, Diwan V, et al. High-carbohydrate, high-fat diet-induced metabolic syndrome and cardiovascular remodeling in rats. J Cardiovasc Pharmacol. 2011; 57: 611-24.

3. Lozano I, Van der Werf R, Bietiger W, Seyfritz E, Peronet C, Pinget $\mathrm{M}$, et al. High-fructose and high-fat diet induced disorders in rats: impact on diabetes risk, hepatic and vascular complications. Nutr Metab (Lond). 2016; 13: 15. doi: 10.1186/s12986-016-0074-1.

4. World Health Organization (WHO) [Internet]. Obesity and Overweight [update 2019 March 3; cited 2019 April 10]. Available from: http://www.who.int/mediacentre/factsheets/fs311/en/.

5. Health Research and Development Board. Riset Kesehatan Dasar. Jakarta: Ministry of Health Republic of Indonesia; 2017.

6. Ronan L, Alexander-Bloch AF, Wagstyl K, Farooqi S, Brayne C, Tyler LK, et al. Obesity associated with increased brain age from midlife. Neurobiol Aging. 2016; 47: 63-70.

7. Francis H, Stevenson R. The longer-term impacts of Western diet on human cognition and the brain. Appetite. 2013; 63: 119-28.

8. Erion JR, Wosiski-Kuhn M, Dey A, Hao S, Davis CL, Pollock NK, et al. Obesity elicits interleukin 1-mediated deficits in hippocampal synaptic plasticity. J Neurosci. 2014; 34: 2618-31.

9. Reinert KRS, Po EK, Barkin SL. The relationship between executive function and obesity in children and adolescents: a systematic literature review. J Obes. 2013; 2013: 1-10. doi: 10.1155/2013/820956.

10. Bove RM, Brick DJ, Healy BC, Mancuso SM, Gerweck AV, Bredella $\mathrm{MA}$, et al. Metabolic and endocrine correlates of cognitive function in healthy young women. Obesity. 2013; 21: 1343-9.

11. Raji CA, Ho AJ, Parikshak NN, Becker JT, Lopez OL, Kuller LH, et al. Brain structure and obesity. Hum Brain Mapp. 2010; 31: 353-64.

12. Bolzenius JD, Laidlaw DH, Cabeen RP, Conturo TE, McMichael $\mathrm{AR}$, Lane EM, et al. Impact of body mass index on neuronal fiber bundle lengths among healthy older adults. Brain Imaging Behav. 2013; 7: 300-6.

13. Bischof GN, Park DC. Obesity and aging: consequences for cognition, brain structure, and brain function. Psychosom Med. 2015; 77: 697709.

14. Birdsill AC,Carlsson CM,Willette AA,Okonkwo OC,Johnson SC,Xu $\mathrm{G}$, et al. Low cerebral blood flow is associated with lower memory function in metabolic syndrome. Obesity. 2013; 21: 1313-20.

15. Waldstein SR, Katzel LI. Interactive relations of central versus total obesity and blood pressure to cognitive function. Int J Obes. 2006; 30: 201-7.

16. Li Y, Dai Q, Jackson JC, Zhang J. Overweight is associated with decreased cognitive functioning among school-age children and adolescents. Obesity. 2008; 16: 1809-15.

17. Francisqueti FV, Santos KC, Ferron AJ, Lo AT, Minatel IO, Campos DH, et al. Fructose: toxic effect on cardiorenal risk factors and redox state. SAGE Open Med. 2017; 4: 1-6. doi: $10.1177 / 2050312116684294$.

18. Koolhaas JM. The laboratory rat. In: Hubrecht R, Kirkwood J. The UFAW Handbook on The Care and Management of Laboratory and Other Research Animals. 8th ed. UK: John Wiley \& Sons, Inc; 2010. p.311-26. 
19. Yoo S, Ahn H, Park YK. High dietary fructose intake on cardiovascular disease related parameters in growing rats. Nutrients. 2017; 9: 11. doi: 10.3390/nu9010011.

20. Handayani D, Meyer BJ, Chen J, Tang P, Kwok PCL, Chan HK, et al. The comparison of the effect of oat and shiitake mushroom powder to prevent body weight gain in rats fed high fat diet. Food Nutr Sci. 2012; 3: 1009-19.

21. Sena CM, Matafome P, Louro T, Nunes E, Seica RM. Effects of atorvastatin and insulin in vascular dysfunction associated with type 2 diabetes. Physiol Res. 2014; 63: 189-97.

22. Ello-Martin JA, Ledikwe JH, Rolls BJ. The influence of food potion size and energy density intake: implications for weight management. J Clin Nutr. 2005; 82: 236-41.

23. La Fleur SE, Luijendijk MC, van Rozen AJ, Kalsbeek A, Adan RA. A free-choice high-fat high-sugar diet induces glucose intolerance and insulin unresponsiveness to a glucose load not explained by obesity. Int J Obes. 2011; 35: 595-604.

24. Crescenzo R, Bianco F, Coppola P, Mazzoli A, Valiante S, Liverini G, et al. Adipose tissue remodeling in rats exhibiting fructose-induced obesity. Eur J Nutr. 2014; 53: 413-9.
25. Ghibaudi L, Cook J, Farley C, van Heek M, Hwa JJ. Fat intake affects adiposity, comorbidity factors, and energy metabolism od Sprague Dawley rats. Obes Res. 2002; 19: 956-63.

26. Björkhem I, Meaney S. Brain cholesterol: long secret life behind a barrier. Arterioscler Thromb Vasc Biol. 2004; 24: 806-15.

27. Adhayani F, Listyaningrum D, Sjahrir H. Hubungan antara profil lipid dan gangguan memori pada usia paruh baya. Neurona. 2013; 31: 850.

28. Yoon J, Gores GJ. Death receptor-mediated apoptosis and the liver. J Hepatol. 2002; 37: 400-10.

29. Duncan GW. 2011. The aging brain and neurodegenerative diseases. Clin Geriatr Med. 2011; 27: 629-44.

30. Kermer P, Liman J, Weishaupt JH, Bahr M. Neuronal apoptosis in neurodegenerative diseases: from basic research to clinical application. Neurodegenerative. 2004; 1: 9-19.

31. Launer LJ, White LR, Petrovitch H, Ross GW, Curb JD. Cholesterol and neuropathologic markers of AD A population-based autopsy study. Neurology. 2001; 57: 1447-52.

32. Kontush A, Chapman MJ. HDL: close to our memories?. J Am Heart Assoc. 2008; 28: 1418-20. 